Research Article

\title{
Strength Characteristics of Nonpenetrating Joint Rock Mass under Different Shear Conditions
}

\author{
Qingzhi Chen, ${ }^{1}$ Yuanming Liu $\mathbb{D}^{1},{ }^{1}$ and Shaoyun $\mathrm{Pu}^{2}$ \\ ${ }^{1}$ School of Civil Engineering, Guizhou University, Guiyang 550003, Guizhou, China \\ ${ }^{2}$ School of Transportation, Southeast University, Nanjing 211189, Jiangsu Province, China \\ Correspondence should be addressed to Yuanming Liu; 845612605@qq.com
}

Received 25 September 2019; Revised 10 July 2020; Accepted 23 July 2020; Published 24 August 2020

Academic Editor: Francesco Colangelo

Copyright (C) 2020 Qingzhi Chen et al. This is an open access article distributed under the Creative Commons Attribution License, which permits unrestricted use, distribution, and reproduction in any medium, provided the original work is properly cited.

The mechanical property of jointed rock mass is an important factor to be considered in the analysis, evaluation, and design of actual rock engineering. The existence of joints threatens the stability and safety of underground engineering projects built in the rock mass. In order to study the change of mechanical properties and strength characteristics of nonpenetrating jointed rock mass under different test conditions, direct shear tests and triaxial tests were carried out. Direct shear tests under different normal stresses were carried out for nonpenetrating jointed rock mass to prepare specimens for triaxial tests. Then, triaxial tests were carried out to study the change of mechanical properties and strength characteristics of the nonpenetrating jointed rock mass. In the direct shear test part, the greater the normal stress is, the stronger the shear strength and the more serious the shear failure would be. The main conclusions are as follows: (1) the strength of rock mass would increase with the increase of confining pressure for those rock specimens with same degrees of shear after the direct shear test; (2) for rock specimens with different degrees of shear after the direct shear test, if the shearing degree of the rock specimen was greater, the strength of the rock specimen would be lower in the triaxial test; (3) for rock specimens with the same damage degree after direct shear test, the greater the normal stress in direct shear test is, the smaller the peak axial pressure would be in the triaxial test; (4) if the specimen was sheared under higher normal stress in direct shear test, the cohesion of it would be lower and the internal friction angle would be larger. For the specimens under the same normal stress, if the shear failure of one specimen was more serious, the cohesion of it would be smaller and the internal friction angle would be larger.

\section{Introduction}

After a long-term unbalanced geological process, the rock mass is heterogeneous, anisotropic. The rock mass is a brittle material with dilatancy [1-4]. In the natural state, rock mass contains irregular and ruleless joints and cracks, and the existing joints and cracks divide rock mass into different blocks $[5,6]$. The mechanical properties of jointed rock mass are quite different from those of intact rock mass, and the typical jointed rock mass is shown in Figure 1. The jointed rock mass can be divided into nonpenetrating jointed rock mass and penetrating jointed rock mass according to whether the internal joint is penetrated $[7,8]$. Studying the mechanical properties of the nonpenetrating jointed rock mass is of great significance for both theoretical study and engineering applications [9].
Due to the discontinuity, anisotropy, inhomogeneity, and other characteristics of rock mass, the rock mass specimens with good integrity and undisturbed mechanical properties are difficult to obtain $[10,11]$. At present, in order to study the mechanical properties of nonpenetrating jointed rock mass, rock-like materials are usually used to replace natural rock materials to prepare test specimens. The rocklike materials are prepared by gypsum or cement mortar and other materials according to a certain ratio. Rock mass joints or cracks are usually formed by adding mica sheets, sheet metal, scraps of paper, or plastic sheets during the rock mass model making process $[7,8,12,13]$. Artificial rock-like materials have many advantages, for example, rock-like materials are easy to produce and obtain, and the preparation process is simpler and easier than the sampling process. Rock-like materials can reflect the brittleness and 

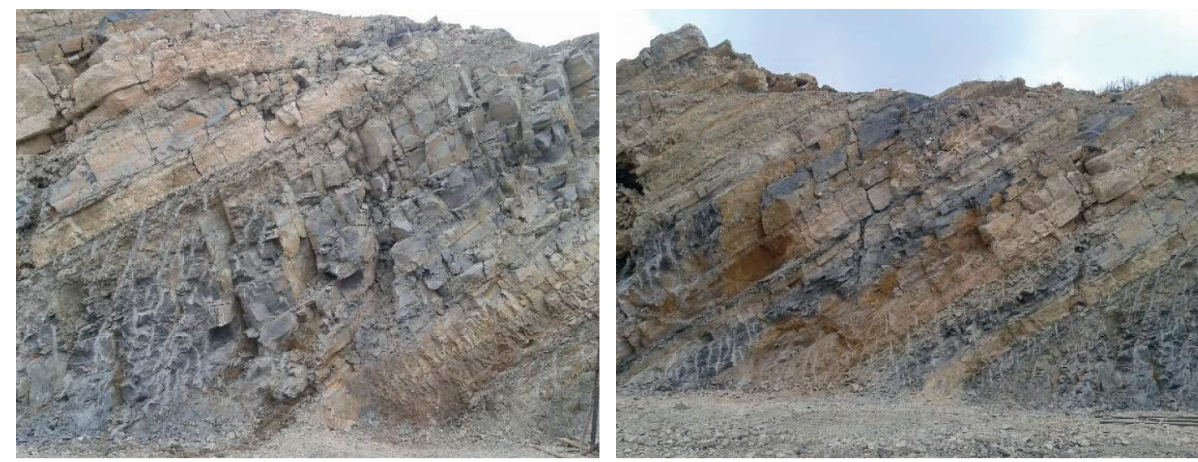

Figure 1: Typical rock mass in engineering. (The picture shows the actual situation of a construction site in Guiyang City, Guizhou Province, China).

dilatancy of rocks, and their mechanical properties are similar to those of conventional rock materials [12-15].

Many scholars have conducted a lot of research on nonpenetrating joints rock mass. Ngo et al. [16] conducted a model test and found that the tensile crack would periodically grow along the side of the shear fracture interface at a substantially constant angle during the experiment and their analytical model explained the generation and tilting of tensile cracks. In this study of Xu et al. [17], gypsum (a soft rock material) was subjected to a compression test to investigate crack propagation and coalescence owing to nonpenetrating surface defects and their influences on material strength. Liu and Xia $[7,8]$ used cement mortar as a rock-like material to make jointed rock mass model, they used nonpenetrating jointed rock masses with three different joint shapes to conduct direct shear tests under five-level normal stress conditions to study the effect of joint morphology on the extended through-deformation and strength characteristics of nonpenetrating jointed rock mass under direct shear conditions, and they divided the breakthrough process of discontinuous jointed rock mass into four stages (see Figure 2). In addition to the above scholars' research, the following scholars have also done research on jointed rock masses. For instance, Du et al. [18] analyzed the interrelationship between the joint deformation properties and deformation history of rocks by shear tests on irregular and artificially fractured granite and sandstone joints in different shear deformation history. Bobet and Einstein [19] used gypsum as a rock-like material to make a jointed rock mass model with two joints and carried out uniaxial and biaxial compression tests to study the mechanical properties of jointed rock mass. In two different test states, they observed the crack propagation and looked for the law and finally concluded the relevant conclusions. Jan et al. [20] used a selfdeveloped special water-injection pressurizing device to pressurize the strata model specimen with a single joint made of rock-like materials according to a certain proportion (the weight ratios of water, fine sand, cement, water repellent are $1: 4: 5: 0.2)$ in the test, and through CT imaging analysis, he studied the damage evolution characteristics of hydraulic fracturing of jointed rock mass from a microscopic point of view and studied the development, expansion, and penetration of the joints inside the jointed rock mass.

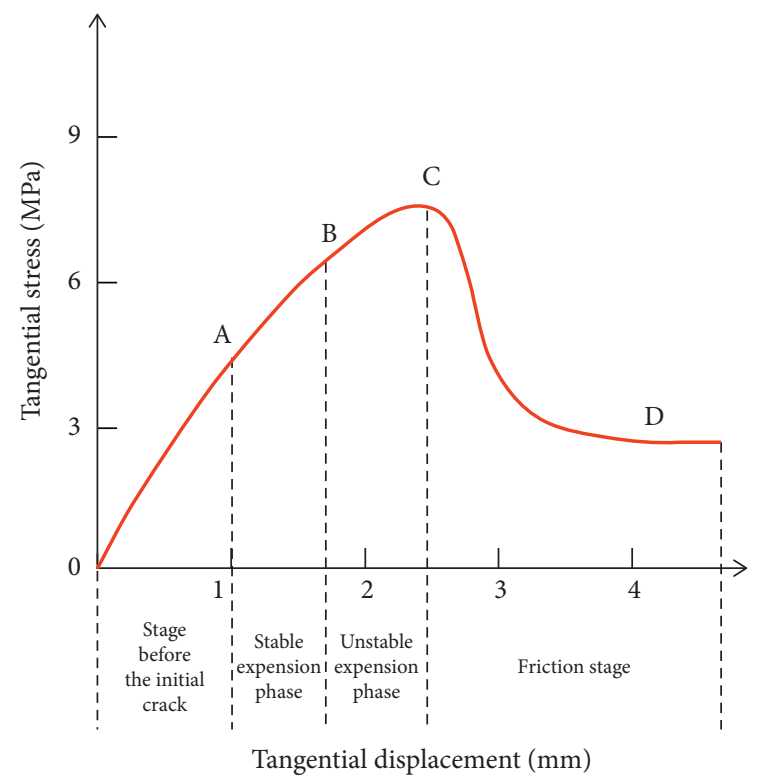

FIGURE 2: Different stages of shear failure of nonpenetrating jointed rock mass [7].

Also, Xia et al. [21], Bai et al. [22], Ren et al. [23], Hu et al. [24], and other experts or scholars [25-33] have used rocklike materials to study the strength characteristics, deformation, and failure mechanism of the rock mass.

Nowadays, for the study of nonpenetrating jointed rock masses, the physical model test is mainly based on a single test method; that is, the nonpenetrating jointed rock mass is studied by a direct shear test or a triaxial loading and unloading test and other mechanical experiment methods [23-32]. Nevertheless, in actual engineering, the stress state of the rock mass is complex, and the rock mass under the natural state is affected by geological action and so subjected to different shearing states. The influence of shear strength of rock mass on its mechanical properties can not be ignored. Therefore, in order to study the mechanical properties of nonpenetrating jointed rock mass under different shear conditions, the cement mortar (mixing water:cement: sand $=1: 2: 3$ ) was used as the rock-like material to produce the nonpenetrating joint rock mass model. Specimens were prepared by direct shear test under different shear states. 
Then, the triaxial test was used to study the mechanical properties of nonpenetrating joint rock mass model through jointed rock mass under different shear states and the influence of rock mass expansion and connection. The results of this study may provide some basis for the correct evaluation of rock mass quality.

\section{Materials and Methods}

2.1. Direct Shear Test. Referring to the above-mentioned articles, this paper also makes reference to other related papers [33-36], then carefully designs and produces nonpenetrating jointed rock mass models to test the related mechanical properties of nonpenetrating mechanism rock masses.

For the direct shear test, the prepared specimens are subjected to different degrees of shear tests under different normal stresses, and the purpose of this test is to prepare for the next triaxial test study.

2.1.1. Preparation of Direct Shear Test Specimens. The mold used for the specimen preparation was cast iron material. The mix proportion of the cement mortar specimen was water: cement : sand $=1: 2: 3$, and the material was mixed by mechanical means. During the pouring of the specimen, the internal coplanar nonpenetrating joint of the rock mass was generated by preembedding the metal strip, and the joint model made of $0.2 \mathrm{~mm}$ thin aluminum sheet was inserted into both sides of the specimen to form a coplanar joint. The joint undulation angle is seen in Figure 3(a)). The joint connectivity rate is the ratio of the length of all joints and the measured line in the extension direction of the plane; it is controlled by the tooth profile angle and the width of the metal strip (see Figure 3(b)). The equation for calculating the joint connectivity is equation (1). The joint undulation angle of the prepared specimen was $15^{\circ}$, the joint connection rate was 0.5 , and the specimen size was $200 \mathrm{~mm} \times 200 \mathrm{~mm} \times 200 \mathrm{~mm}$. The preparation process of the specimen referred to the articles $[37,38]$, and the basic flow is shown in Figure 4. The mechanical parameters of the cement mortar specimen used in this test were measured after 28 days of standard curing (see Table 1).

$$
j=\frac{2 s}{L},
$$

where $j$ is joint connectivity rate; $s$ is the length of a single joint; $(\mathrm{mm}) . L$ is the length of the measured line; $(\mathrm{mm})$. (Note. The $L$ used in this test is the fixed value, $L=200 \mathrm{~mm}$ ).

The mechanical parameters of this kind of rock material are compared with the basic mechanical parameters of rocklike material used in the previous study of mechanical properties of nonpenetrating jointed rock mass $[7,8,39]$. The comparison results are relatively close. In addition, the mechanical parameters of the rock-like materials used in this study are compared with the basic mechanical properties of common rock materials, and it is found that the two are of the same order of magnitude. This shows that the rock-like materials used in this study can simulate rock materials [40-44].

2.1.2. Direct Shear Test Procedure. The rock and concrete mechanical test system RMT-301 developed by the Institute of Rock and Soil Mechanics, Chinese Academy of Sciences (see Figure 5), was used during the direct shear test. The test process can be completely controlled by a computer when RMT-301 is used. However, after changing the control mode and test parameters, the operator can also intervene in the experimental process and manually control the start and end of the test. Therefore, RMT-301 can be used to obtain rock specimens in different shear states conveniently. This provides support for the determination of mechanical parameters of nonpenetrating jointed rock mass under different shear states by triaxial test.

The normal stress in the direct shear test was divided into five levels, namely, 0.5 MPa, 1.0 MPa, 1.5 MPa, 2 MPa, and $3 \mathrm{MPa}$. During the test, when the applied normal load tended to be stable, the horizontal load was applied, and the direct shear test was carried out at a horizontal displacement rate of $0.01 \mathrm{~mm} / \mathrm{s}$ until the specimen was destroyed. The loading position is shown in Figure 6. In order to make the test results more reliable, each test was repeated 3 times, and the test data obtained from 3 specimens were weighted averaged (If one of the data in the same group was found to be significantly different, the other two data that are close to each other would be selected for weighted average). The shear displacement-shear stress curves of the nonpenetrating jointed rock mass under different normal stresses are obtained (see Figure 7).

With reference to Figures 2 and 7 , a set of specimens with joints with an undulation angle of $15^{\circ}$ and a connectivity ratio of 0.5 were selected; then direct shear tests with normal stresses of $0.5 \mathrm{MPa}$ and $1.5 \mathrm{MPa}$ were performed, respectively. During the direct shear tests, once the specimen reached the specified shear state, the test would be ended artificially. In other words, when the specimen reached the endpoint $B$ or point $C$ of the shear stress that is shown in Figure 2, the direct shear test would be ended artificially. Then, the specimens are removed to be processed for the triaxial test. The scheme of each group of the direct shear test is as follows:

(1) The First Group. Three rock mass specimens were selected and the normal stress was set to $0.5 \mathrm{MPa}$. When the applied normal load became stable, the horizontal load was applied, and the direct shear test was carried out at a horizontal displacement rate of $0.01 \mathrm{~mm} / \mathrm{s}$. When the shear state of the specimen reached point B (see Figure 2), the direct shear test was stopped.

(2) The Second Group. Three rock mass specimens were selected and the normal stress was set to $1.5 \mathrm{MPa}$. When the applied normal load became stable, the horizontal load was applied, and the direct shear test was carried out at a horizontal displacement rate of $0.01 \mathrm{~mm} / \mathrm{s}$. Before the shear 


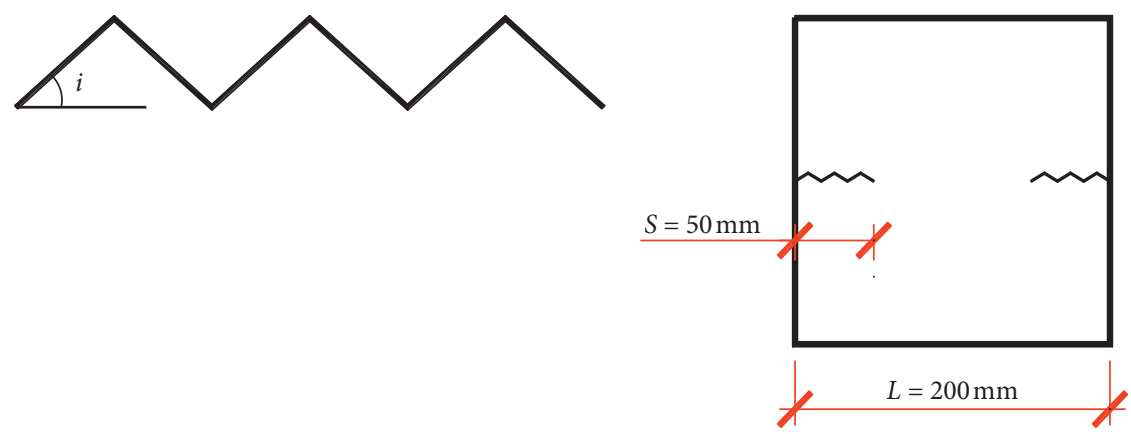

(a)

(b)

Figure 3: Details of the coplanar jointed rock mass. (a) Coplanar joint undulation angle. (b) Schematic diagram of coplanar joint connectivity.

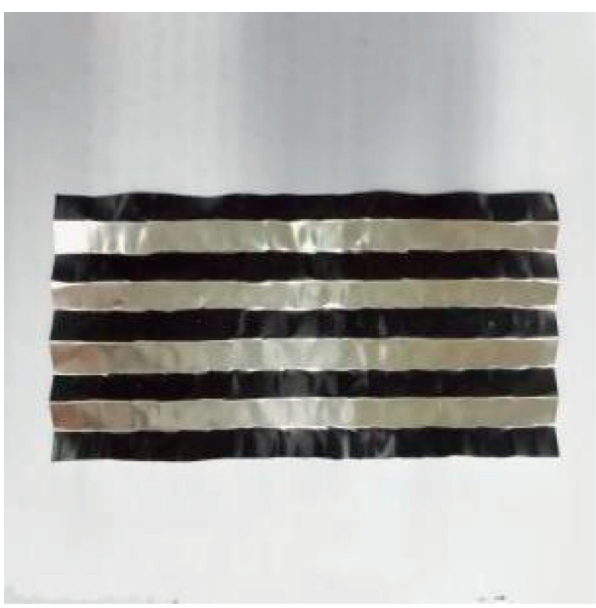

(a)

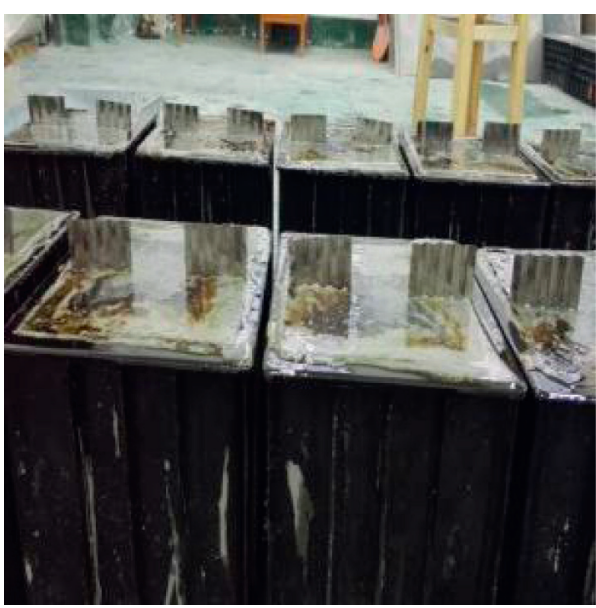

(c)

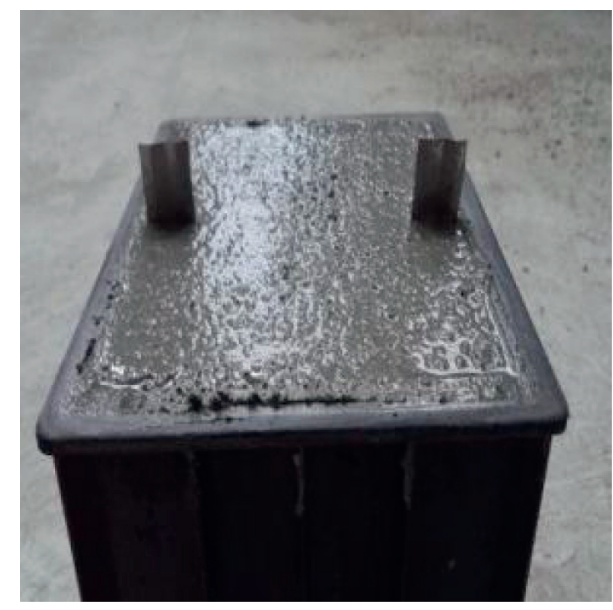

(b)

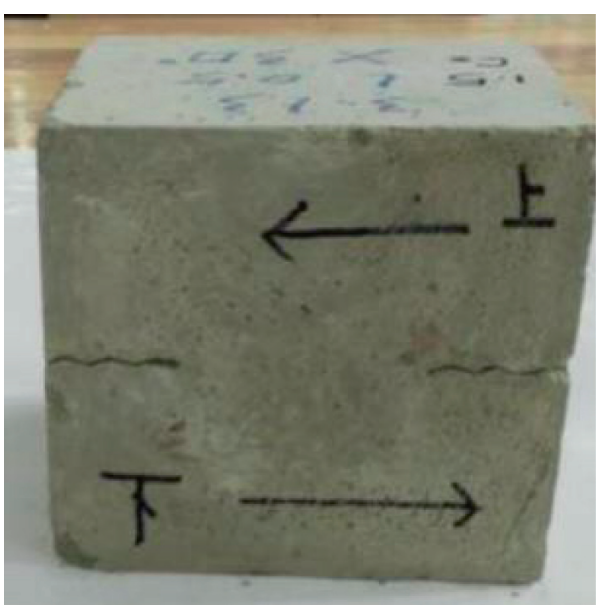

(d)

Figure 4: Specimen preparation process [38]. (a) Making a joint model. (b) Pouring specimen. (c) Model maintenance. (d) Model preparation completed.

TABLE 1: Mechanical parameters of rock-like materials used.

\begin{tabular}{|c|c|c|c|c|c|c|c|}
\hline Mix ratio (quality) & $\begin{array}{l}\text { Density } \\
\left(\mathrm{g} / \mathrm{cm}^{3}\right)\end{array}$ & $\begin{array}{l}\text { Compressive } \\
\text { strength }(\mathrm{GPa})\end{array}$ & $\begin{array}{c}\text { Tensile strength } \\
(\mathrm{GPa})\end{array}$ & $\begin{array}{c}\text { Elastic modulus } \\
(\mathrm{GPa})\end{array}$ & $\begin{array}{l}\text { Poisson's } \\
\text { ratio }\end{array}$ & $\begin{array}{c}\text { Cohesion } \\
(\mathrm{GPa})\end{array}$ & $\begin{array}{c}\text { Internal friction } \\
\text { angle }\left({ }^{\circ}\right)\end{array}$ \\
\hline $\begin{array}{l}\text { Water: cement: } \\
\text { sand }=1: 2: 3\end{array}$ & 2.74 & 44.86 & 2.97 & 8.85 & 0.31 & 15.32 & 46.5 \\
\hline
\end{tabular}




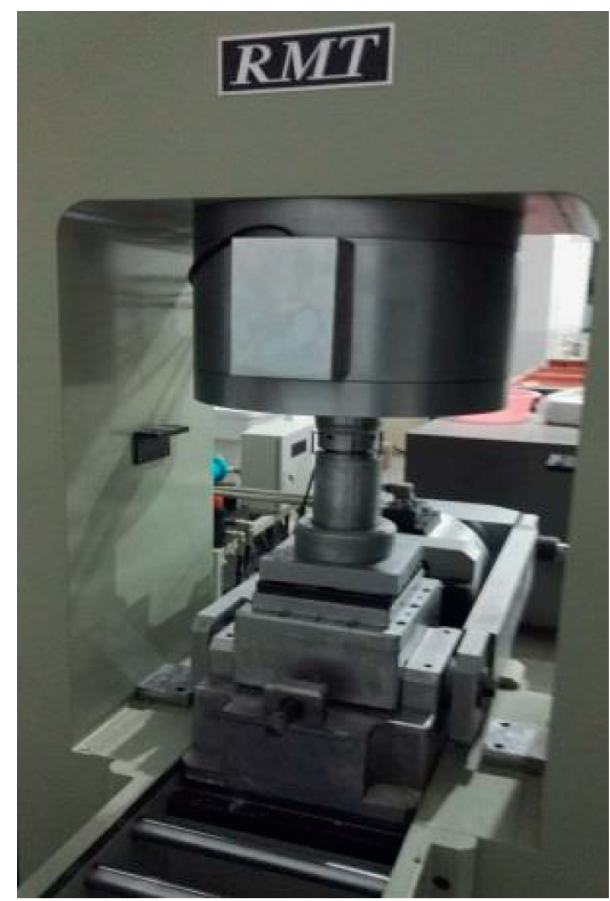

FIgURE 5: RMT-301 mechanics test system for rock and concrete.

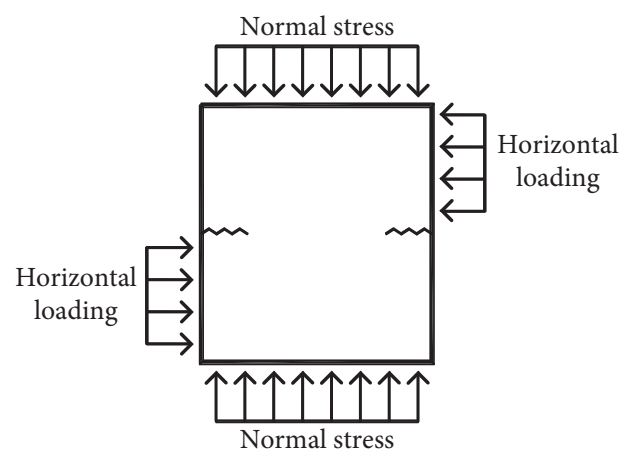

FIgURE 6: Test loading mode.

state of the specimen reached point B (see Figure 2), the instrument is manually controlled to stop shearing.

(3) The Third Group. Six rock mass specimens were selected and the normal stress was set to $0.5 \mathrm{MPa}$. When the applied normal load became stable, the horizontal load was applied, and the direct shear test was carried out at a horizontal displacement rate of $0.01 \mathrm{~mm} / \mathrm{s}$. Before the shear state of the specimen reached point $\mathrm{C}$ (see Figure 2), the instrument was manually controlled to stop shearing.

(4) The Fourth Group. Six rock mass specimens were selected and the normal stress was set to $1.5 \mathrm{MPa}$. When the applied normal load became stable, the horizontal load was applied, and the direct shear test was carried out at a horizontal displacement rate of $0.01 \mathrm{~mm} / \mathrm{s}$. Before the shear state of the specimen reached point $\mathrm{C}$ (see Figure 2), the instrument was manually controlled to stop shearing.

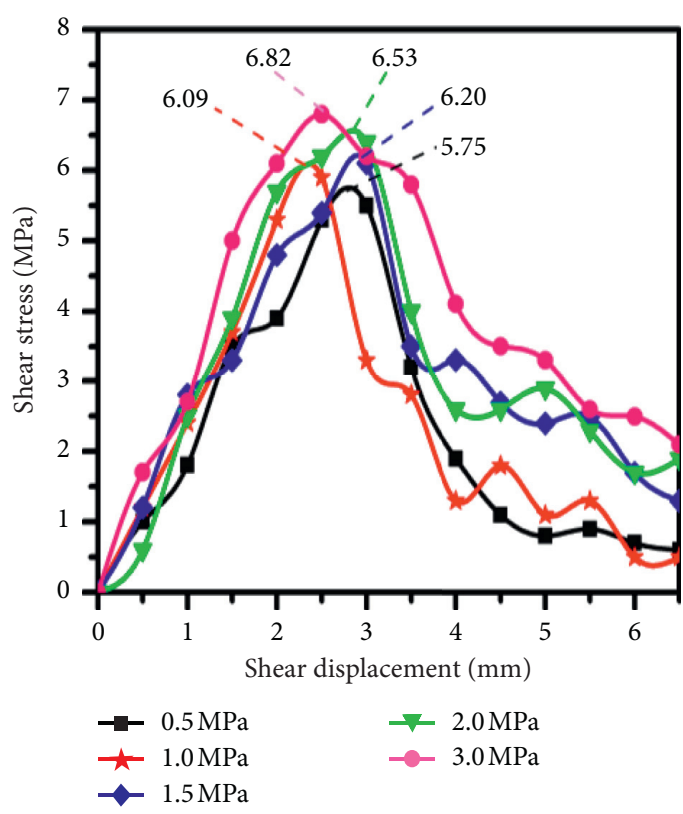

FIgURE 7: Complete shear-displacement-shear stress curves of nonpenetrating jointed rock mass under different normal stress states.

\subsection{Triaxial Test}

2.2.1. Triaxial Test Specimen Preparation. In order to study the influence of confining pressure on rock mass strength during the triaxial test, the specimens that have been subjected to different degrees of the shear test were drilled, cut, and polished for the triaxial test (see Figure 8). The final specimen for the triaxial test is shown in Figure 9.

2.2.2. Triaxial Test Method. The triaxial test used the MTS rock mechanics comprehensive test system, as shown in Figure 10. During the test loading process, the initial confining pressure was first added to the design value, and then the axial load was slowly increased. The loading rate of confining pressure was controlled at $0.5-1.0 \mathrm{MPa} / \mathrm{s}$. The loading rate of axial pressure was controlled by controlling the change rate of axial displacement as $0.1 \mathrm{~mm} / \mathrm{min}$ until the specimen was damaged.

During the test loading process, the initial confining pressure was first added to the design value, and then the axial load was slowly increased, with a loading rate controlled at $0.5-1.0 \mathrm{MPa} / \mathrm{s}$. The axial displacement was used to control the application of the axial load at a loading rate of $0.1 \mathrm{~mm} / \mathrm{min}$ until the specimen was destroyed.

A total of 4 groups of 16 tests were selected for the triaxial test. For the test plan, all specimens were numbered according to the group-sort within group-containment pressure. For example, the meaning of the specimen number of B1-2-3 is as follows: this specimen belongs to the first group of experiments, it is the second specimen in the first group; the confining pressure used in the triaxial test is $3 \mathrm{MPa}$. 


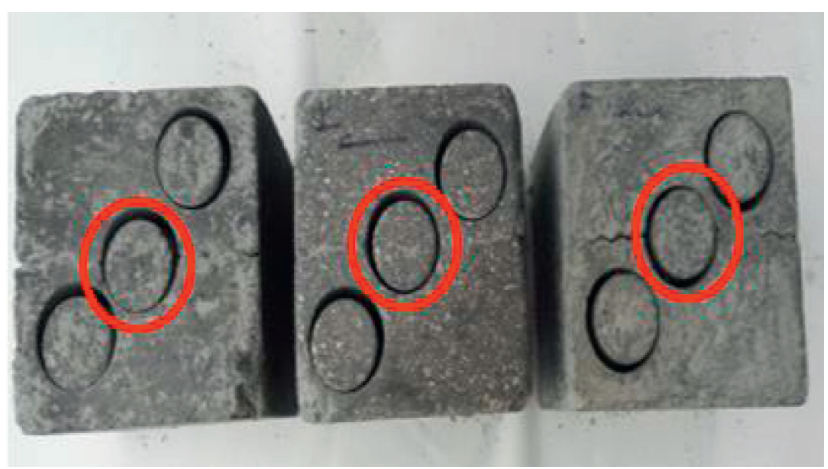

(a)

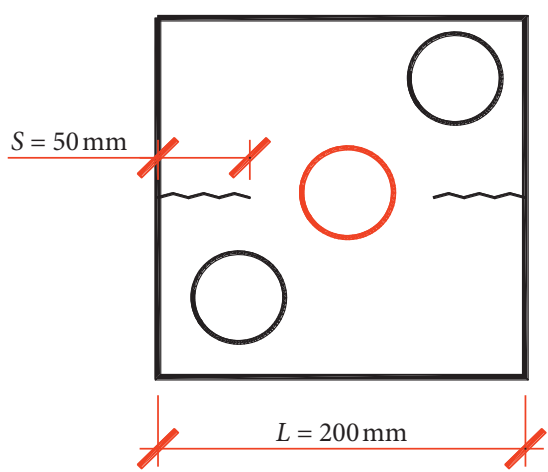

(b)

FIgURE 8: (a) Making specimens for the triaxial test. (b) Schematic diagram of sample drilling position.

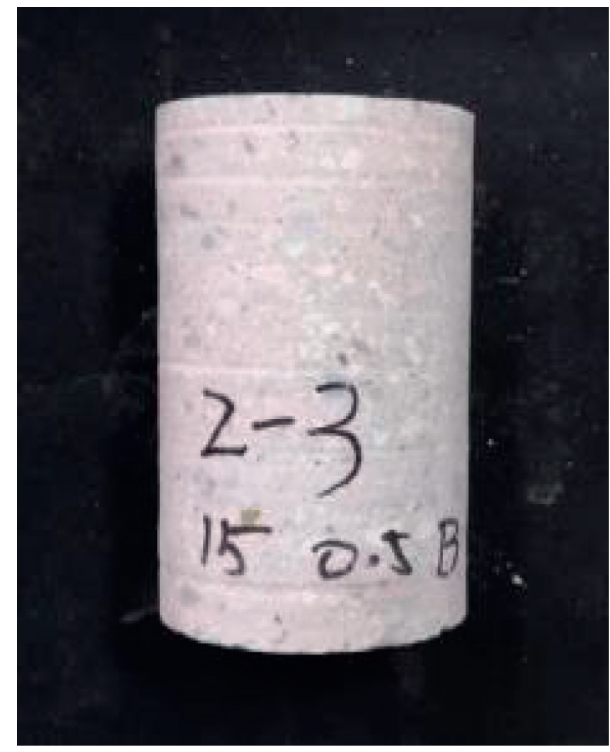

FIGURE 9: Specimen for the triaxial test. (Note. The diameter of the specimen is $50 \mathrm{~mm}$, and the height of the specimen is $100 \mathrm{~mm}$ ).

The summary is shown in Table 2:

(1) The first set of specimens (B1-1-1, B1-2-3, and B1-35) for the triaxial test were processed from the first group of specimens in the direct shear test

(2) The second set of specimens (B2-1-2, B2-2-4, and B2-3-6) for the triaxial test were processed from the second group of specimens in the direct shear test

(3) The third set of specimens (C1-1-1, C1-2-2, C1-3-3, C1-4-4, C1-5-5) for the triaxial test were processed from the third group of specimens in the direct shear test

(4) The fourth set of specimens (C2-1-1, C2-2-2, C2-3-3, $\mathrm{C} 2-4-4, \mathrm{C} 2-5-5)$ for the triaxial test were processed from the fourth group of specimens in the direct shear test

Finally, the specimens required for the four sets of triaxial tests were obtained (see Figure 11).

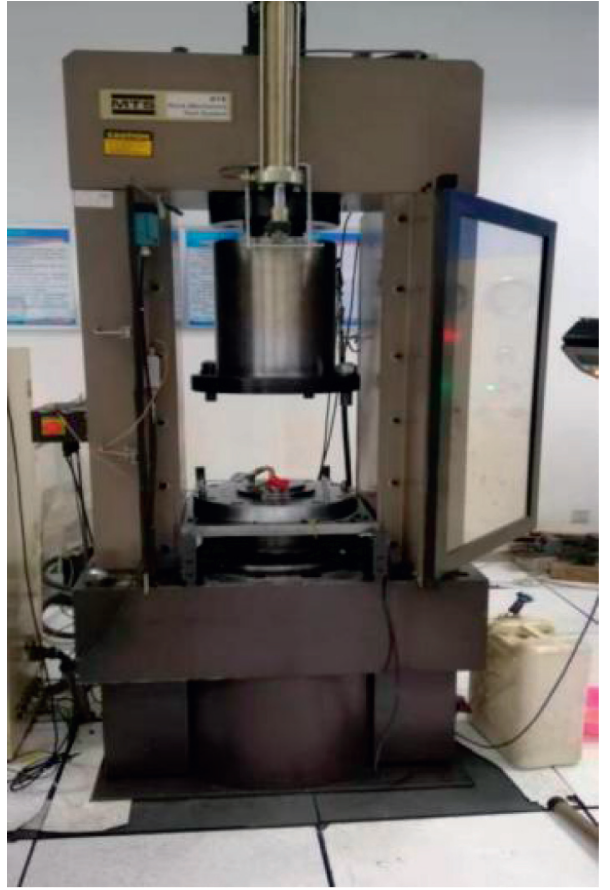

FIGURE 10: MTS rock mechanics comprehensive test system.

\section{Results and Discussion}

3.1. Results and Discussion of Direct Shear Test. The direct shear test obtained the shear displacement-shear stress curves of the nonpenetrating jointed rock mass under different normal stress states as shown in Figure 7. The peak shear stress of each group of specimens is shown in Table 3. It can be seen from Figure 7 and Table 3 that when a nonpenetrating jointed rock mass specimen with a joint undulation angle of $15^{\circ}$ and a joint connection ratio of 0.5 is subjected to a direct shear test, the peak shear stress increases.

3.2. Results and Discussion of Triaxial Test. In Figure 12, only three specimens in the first group (B-1-1-1, B-1-2-3, and B-1-3-5) are taken as examples to show the failure state of the specimen after the triaxial test. 
TABLE 2: Summary of specimen numbers.

\begin{tabular}{|c|c|c|c|c|c|c|}
\hline \multirow{2}{*}{$\begin{array}{l}\text { State during direct shear test } \\
\text { Damage degree }\end{array}$} & \multicolumn{6}{|c|}{ Test piece number } \\
\hline & Normal stress $(\mathrm{MPa})$ & & & & & \\
\hline \multirow{2}{*}{ Point B } & 0.5 & B1-1-1 & B1-2-3 & B1-3-5 & & \\
\hline & 1.5 & B2-1-2 & B2-2-4 & B2-3-6 & & \\
\hline \multirow{2}{*}{ Point C } & 0.5 & C1-1-1 & C1-2-2 & $\mathrm{C} 1-3-3$ & C1-4-4 & C1-5-5 \\
\hline & 1.5 & C2-1-1 & C2-2-2 & C2-3-3 & C2-4-4 & C2-5-5 \\
\hline
\end{tabular}

Note. The last digit of the specimen number indicates the size of the confining pressure applied during the triaxial test.

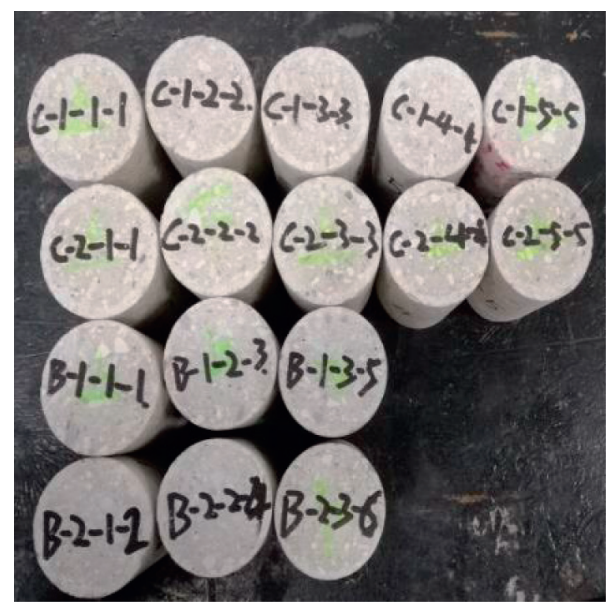

FIGURE 11: Specimens required for triaxial testing.

TABle 3: Peak shear stress statistics of each group.

\begin{tabular}{lccccc}
\hline Normal stress $(\mathrm{MPa})$ & 0.5 & 1 & 1.5 & 2 & 3 \\
\hline Peak shear stress $(\mathrm{MPa})$ & 5.75 & 6.09 & 6.20 & 6.53 & 6.82 \\
\hline
\end{tabular}
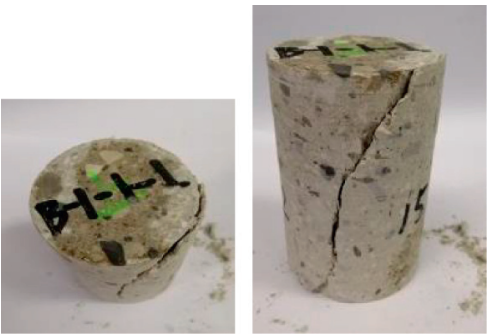

(a)

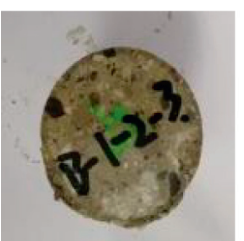

(b)

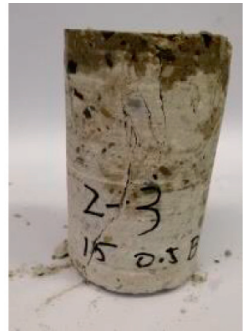

(b)

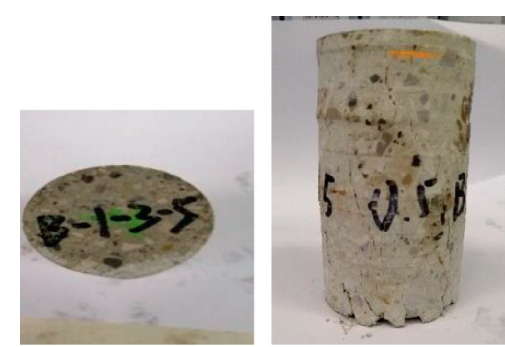

(c)

Figure 12: The failure state of some specimens. (a) The state of the specimen B-1-1-1 after the triaxial test. (b) The state of the specimen B-12-3 after the triaxial test. (c) The state of the specimen B-1-3-5 after the triaxial test.

By observing the final state of these four groups of specimens, it is found that in the triaxial test, the larger the confining pressure of the specimens in each group of tests, the smaller the final degree of failure of the specimen and the finer the vertical cracks.

Figures 13-16 shows the axial displacement-axial stress curves of each group of specimens obtained by triaxial test. The peak axial stress of each group of specimens under different confining pressures is shown in Table 4.

For the nonpenetrating jointed rock mass with the same normal stress and the same degree of shear failure in the direct shear test, the strength under the triaxial condition increases with the increase of the confining pressure. The test results of the B1 group are taken as an example for analysis. When the confining pressure is $1 \mathrm{MPa}$, the peak axial pressure is $56.86 \mathrm{MPa}$. When the confining pressure is $3 \mathrm{MPa}$, the peak axial pressure is $61.23 \mathrm{MPa}$. When the confining pressure is $5 \mathrm{MPa}$, the peak axial pressure is $70.88 \mathrm{MPa}$. It could be seen that with the increase of the confining pressure $\sigma 3$, the peak stress $\sigma 1$ when the rock mass destroyed gradually increased, and the test groups B2, C1, and $\mathrm{C} 2$ have the same law. Therefore, for the nonpenetrating 


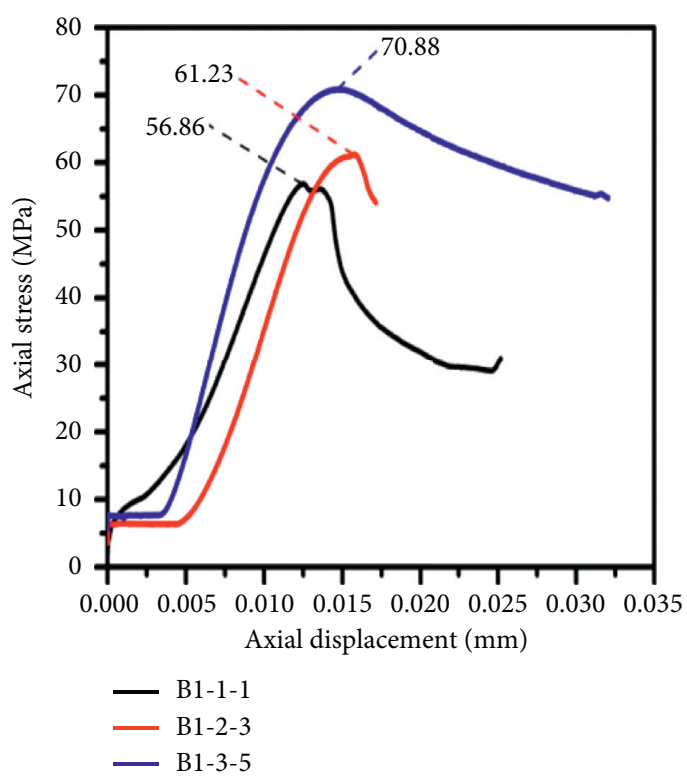

Figure 13: Axial displacement-axial stress curve of group B1.

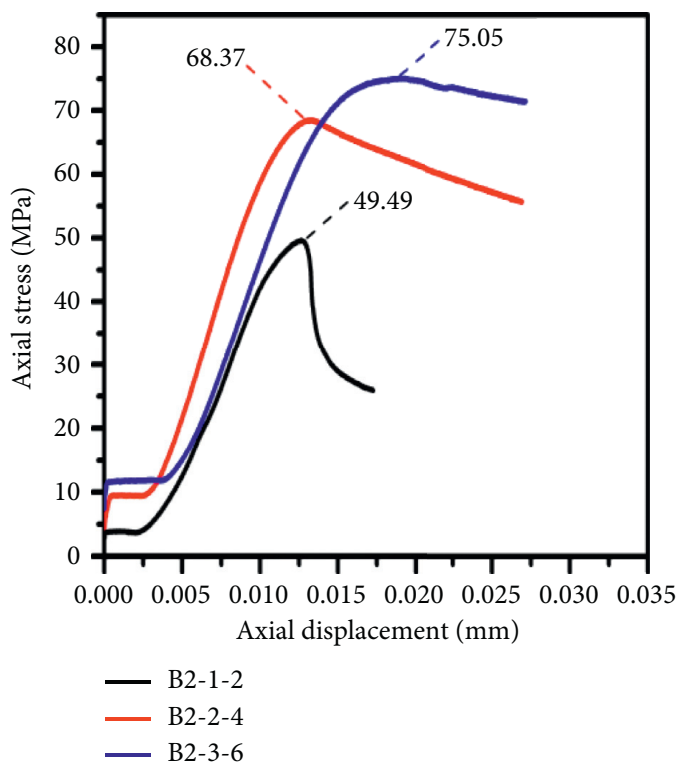

Figure 14: Axial displacement-axial stress curve of group B2.

jointed rock mass, the larger the confining pressure of the nonpenetrating jointed rock mass under the same shear state, the stronger the axial compressive strength.

For nonpenetrating jointed rock masses with uniform normal stress and different degree of shear failure during direct shear test, the greater the degree of shear failure, the lower the peak strength will be in the triaxial test. Comparing the test data of B1-1-1 and C1-1-1, it can be found that the peak axial pressure of $\mathrm{B} 1-1-1$ is $56.88 \mathrm{MPa}$ and that of $\mathrm{C} 1-1-1$ is $51.62 \mathrm{MPa}$ when the confining pressure of triaxial test is $1 \mathrm{MPa}$. That is to say, the peak axial pressure of specimens with damage degree reaching point $B$ is greater than that of specimens with damage degree reaching point $\mathrm{C}$. The same rule exists in comparison with the tests of $\mathrm{B} 1-2-3, \mathrm{C} 1-3-3$,

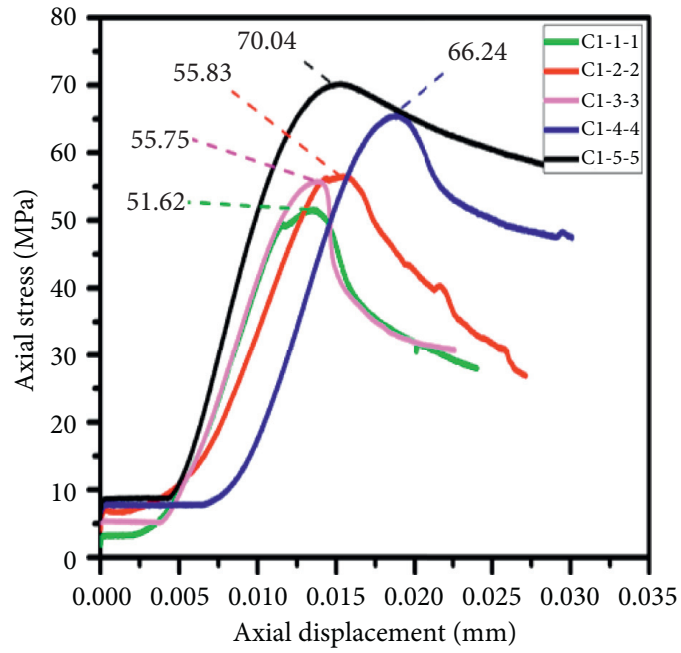

Figure 15: Axial displacement-axial stress curve of group C1.

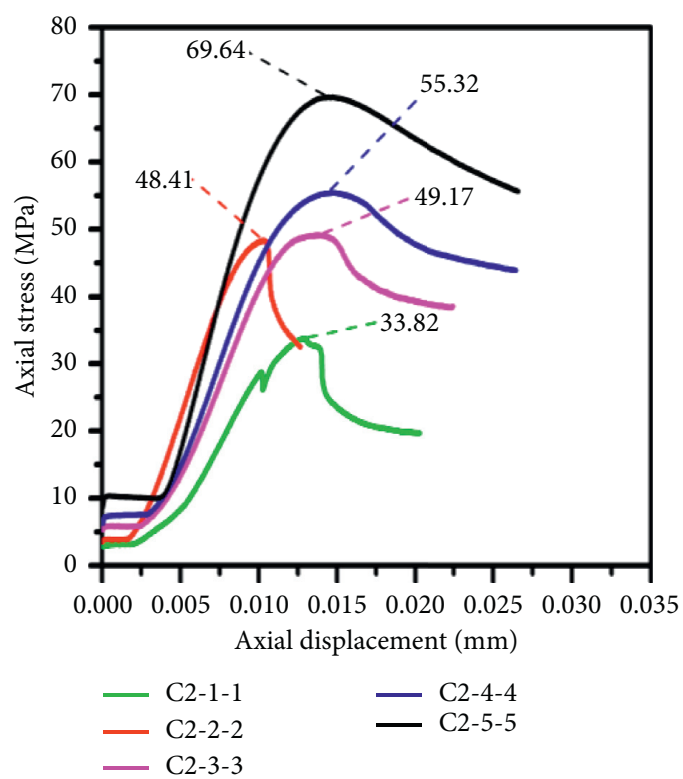

Figure 16: Axial displacement-axial stress curve of group C2.

B1-3-5, and C1-5-5. It can be concluded that the more serious the shear disturbance is, the lower the peak strength of the triaxial test is.

For nonconnected jointed rock mass with inconsistent normal stress and the same degree of shear failure in direct shear test, the greater the normal stress in direct shear test, the smaller the peak axial strength obtained in the later triaxial test. Comparing the test results of C1-1-1 and C2-1-1 specimens, it can be seen that the peak axial pressure of $\mathrm{C} 1$ 1-1 specimens is $51.62 \mathrm{MPa}$ when the normal stress is $0.5 \mathrm{MPa}$ controlled by the direct shear test. When the normal stress is controlled by a direct shear test at $1.5 \mathrm{MPa}$, the peak axial pressure of specimen C2-1-1 during the triaxial test is $33.82 \mathrm{MPa}$. That is, the larger the normal stress in the direct shear test, the smaller the axial peak strength of the specimen 


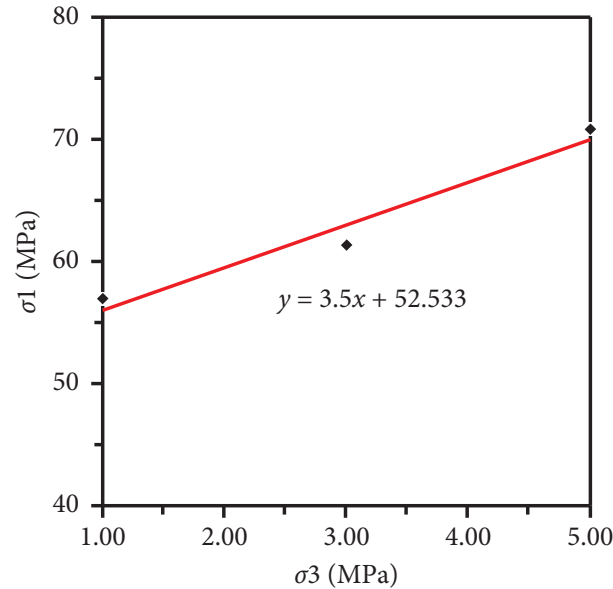

(a)

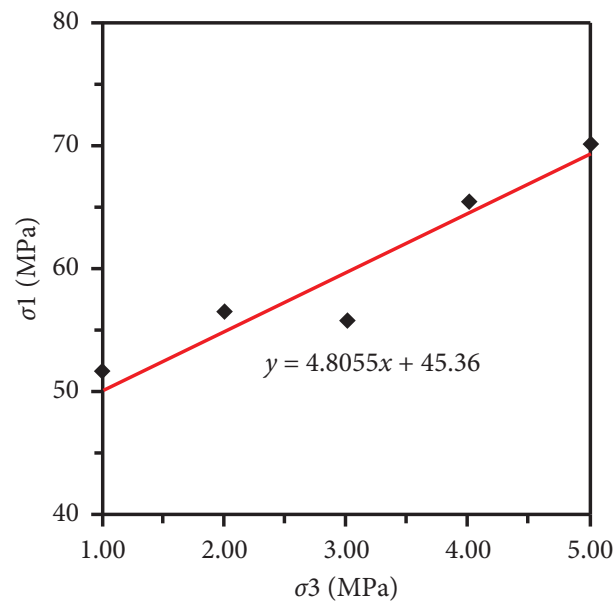

(c)

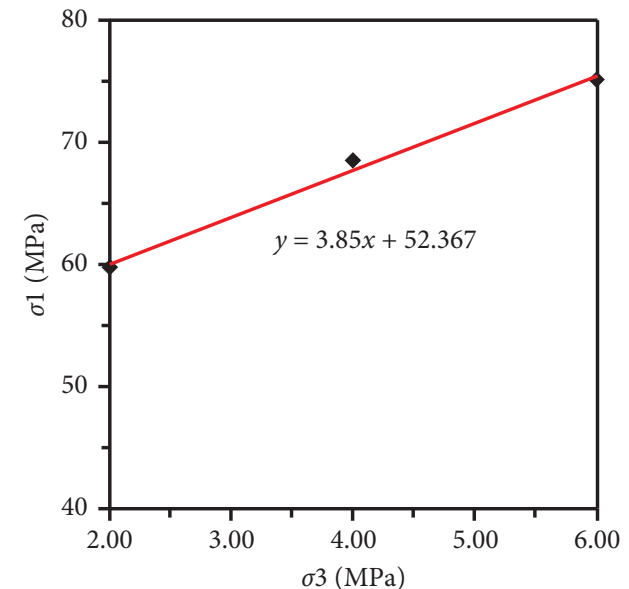

(b)

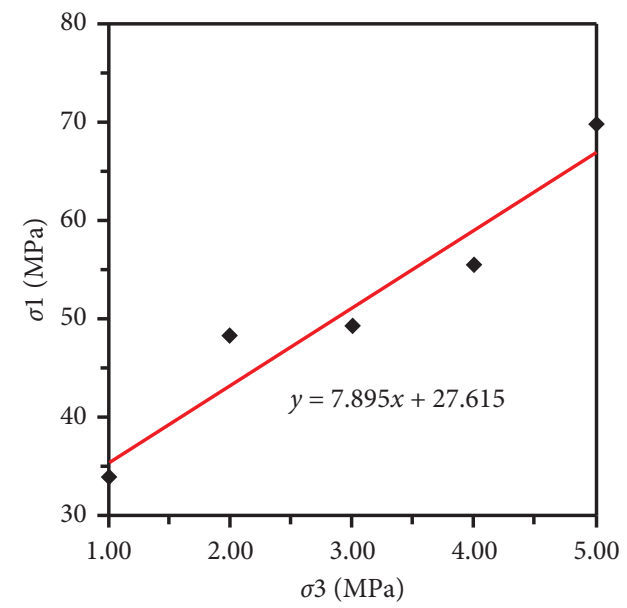

(d)

FIGURE 17: $\sigma 1-\sigma 3$ relationship curves of nonpenetrating jointed rock masses in each group. (a) B1 group $\sigma 1-\sigma 3$ relationship curve. (b) B2 group $\sigma 1-\sigma 3$ relationship curve. (c) C1 group $\sigma 1-\sigma 3$ relationship curve. (d) C2 group $\sigma 1-\sigma 3$ relationship curve.

TABLE 5: The $c$ and $\varphi$ values of each group of the rock mass.

\begin{tabular}{lcccc}
\hline & Group B1 & Group B2 & Group C1 & Group C2 \\
\hline$c(\mathrm{MPa})$ & 14.040 & 13.344 & 10.346 & 4.914 \\
$\varphi\left({ }^{\circ}\right)$ & 33.749 & 35.989 & 40.957 & 50.819 \\
\hline
\end{tabular}

when the obtained specimen is subjected to the triaxial test. That is to say, the greater the normal stress in the direct shear test, the smaller the axial peak strength of the obtained specimens in the triaxial test. The same rule can be obtained by comparing the test data of four groups of specimens, $\mathrm{C} 1$ 2-2, C2-1-2 or C1-3-3, C2-3-3 or C1-4, C2-4-4, or C1-5, C2$5-5$. It can be seen that the greater the normal stress in the direct shear test, the more severe the shear of the rock mass, and the weaker the strength of the specimen after shearing.

From the above test results, the cohesion $c$ and internal friction angle $\varphi$ of the nonpenetrating jointed rock mass under various working conditions were calculated by the equations (1), (2a) and (2b). The strength characteristics of the nonpenetrating jointed rock mass were studied by comparing the internal friction angle and cohesion. The calculation process is as follows.

Taking axial pressure $\sigma 1$ of each specimen as the ordinate and the test confining pressure $\sigma 3$ as the abscissa, the optimal relationship curve (see Figure 17) of the data points of each group of tests (four groups of B1, B2, C1, and C2) was plotted by graphical method. The cohesion $c$ and the internal friction angle $\varphi$ of the rock masses in each group were obtained according to the following equation:

$$
\begin{aligned}
& c=\frac{\sigma_{c}(1-\sin j)}{2 \cos j}, \\
& j=\arcsin \frac{m-1}{m+1},
\end{aligned}
$$

where $c$ is the cohesion of the rock, $\mathrm{MPa} ; \varphi$ is the internal friction angle of the rock, $\left({ }^{\circ}\right) ; \sigma_{\mathrm{c}}$ is the intercept of the optimal relationship curve on the ordinate, $\mathrm{MPa} ; m$ is the slope of the optimal relationship curve.

The values of $c$ and $\varphi$ of the rock masses in the three groups were calculated, as shown in Table 5. 
From the data in Table 5, comparing the test data of B1 and $\mathrm{B} 2$ groups or $\mathrm{C} 1$ and $\mathrm{C} 2$ groups, it can be found that the cohesion of the specimens sheared under higher normal stress is smaller and the internal friction angle is larger in the direct shear test. Comparing the test data of B1 and $\mathrm{C} 1$ or B2 and $\mathrm{C} 2$ groups, it can be seen that for nonpenetrating jointed rock mass sheared under the same normal stress in direct shear test, the more serious the damage degree is, the smaller the cohesion and the larger the internal friction angle is.

It should be pointed out that due to the difficulty in sampling rock mass, this paper uses cement mortar to make rock-like materials instead of natural rock materials. The shear rate of the instrument was quite low when the shear test and triaxial test were performed, and the laws that ultimately emerged from physical tests had limitations. However, this study still has certain reference value for the study of the mechanical properties of the nonpenetrating jointed rock mass.

\section{Conclusions}

In order to study the mechanical properties of nonpenetrating jointed rock mass under complex stress state, shear tests of nonpenetrating jointed rock mass under different working conditions were carried out, and specimens subjected to different shear failure states were obtained. The mechanical properties of rock specimens subjected to different damage degrees are studied by the triaxial test. The following conclusions are drawn from the study:

(1) With the greater normal stress of the nonpenetrating jointed rock mass, the shear strength of the rock mass will be stronger and the shear failure of the rock mass will be more severe.

(2) For the nonpenetrating jointed rock mass with the same normal stress and the same degree of shear failure in the direct shear test, the strength under triaxial conditions increases with the increasing confining pressure.

(3) For nonpenetrating jointed rock masses with uniform normal stress and different degree of shear failure, the triaxial strength will be lower with stronger shear.

(4) For the nonpenetrating jointed rock mass with the same normal stress and the same degree of shear failure, the normal axial stress will increase with the increase of the normal stress in the direct shear test.

(5) With the reduction of the cohesion $c$, the internal friction angle $\varphi$ increases. For the nonpenetrating jointed rock mass sheared under the same normal stress, the more severe the shear, the smaller the cohesion $c$, and the larger the internal friction angle $\varphi$.

\section{Data Availability}

The data used to support the findings of this study are available within this article.

\section{Conflicts of Interest}

The authors declare that they have no conflicts of interest in this work.

\section{Acknowledgments}

This work was supported by the National Natural Science Foundation Project (11562005), the First Class Discipline Construction Project of Civil Engineering in Guizhou Province (QYNYL [2017] 0013), the Natural Science Foundation of Guizhou Province (qkeheji [2019] No. 1057), and Major Scientific and Technological Projects of Guizhou Province (Qiankehe major special project [2018] 3011).

\section{References}

[1] L. Boumaiza, A. Saeidi, and M. Quirion, "Determining relative block structure rating for rock erodibility evaluation in the case of non-orthogonal joint sets," Journal of Rock Mechanics and Geotechnical Engineering, vol. 11, no. 1, pp. 72-87, 2019.

[2] M. Liu and E. Liu, "Dynamic mechanical properties of artificial jointed rock samples subjected to cyclic triaxial loading," International Journal of Rock Mechanics and Mining Sciences, vol. 98, pp. 54-66, 2017.

[3] X. Chen, Z. Liao, and X. Peng, "Deformability characteristics of jointed rock masses under uniaxial compression," International Journal of Mining Science and Technology, vol. 22, no. 2, pp. 213-221, 2012.

[4] Y. Zhang, Z. Zhang, S. Xue, M. Wang, and M. Xiao, "Stability analysis of a typical landslide mass in the Three Gorges Reservoir under varying reservoir water levels," Environmental Earth Sciences, vol. 79, no. 1, p. 42, 2020.

[5] P. T. Wang, F. H. Ren, S. J. Miao, M. Cai, and T. Yang, "Evaluation of the anisotropy and directionality of a jointed rock mass under numerical direct shear tests," Engineering Geology, vol. 225, pp. 29-41, 2017.

[6] M. Bahaaddini, G. Sharrock, and B. K. Hebblewhite, "Numerical direct shear tests to model the shear behaviour of rock joints," Computers and Geotechnics, vol. 51, pp. 101-115, 2013.

[7] Y. M. Liu and C. C. Xia, "Direct shear test of non-connected jointed rock mass based on weakening mechanism of mechanical properties of rock bridges," Journal of Rock Mechanics and Engineering, vol. 29, no. 7, pp. 1467-1472, 2010.

[8] Y. M. Liu and C. C. Xia, "Preliminary study on weakening mechanism of mechanical properties and penetration model of rock bridge in nonpenetrating jointed rock mass under direct shear condition," Geotechnical Mechanics, vol. 31, no. 3, pp. 695-701, 2010.

[9] Z. Zhang, X. Jin, and W. Luo, "Mechanical responses of shotcrete specimens in direct shear tests," Construction and Building Materials, vol. 188, pp. 305-313, 2018.

[10] M. Stavropoulou, "Discontinuity frequency and block volume distribution in rock masses," International Journal of Rock Mechanics and Mining Sciences, vol. 65, pp. 62-74, 2014.

[11] F. Fabbrocino, I. Farina, and M. Modano, "Loading noise effects on the system identification of composite structures by dynamic tests with vibrodyne," Composites Part B Engineering, vol. 115, 2017.

[12] K. Hong, E. Han, and K. Kang, "Determination of geological strength index of jointed rock mass based on image processing," Journal of Rock Mechanics and Geotechnical Engineering, vol. 9, no. 4, pp. 702-708, 2017. 
[13] J. Wang, D. Niu, and Y. Zhang, "Mechanical properties, permeability and durability of accelerated shotcrete," Construction and Building Materials, vol. 95, pp. 312-328, 2015.

[14] P. Migoń, F. Duszyński, and A. Goudie, "Rock cities and ruiniform relief: forms-processes-terminologyw," EarthScience Reviews, vol. 171, pp. 78-104, 2017.

[15] S. Q. Yang, P. F. Yin, Y. H. Huang, and J. L. Cheng, "Strength, deformability and X-ray micro-ct observations of transversely isotropic composite rock under different confining pressures," Engineering Fracture Mechanics, vol. 214, pp. 1-20, 2019.

[16] D. Ngo, Y. Huang, A. Rosakis, W. A. Griffith, and D. D. Pollard, "Off-fault tensile cracks: a link between geological fault observations, experiments and earthquake rupture models," Journal of Geophysical Research Solid Earth, vol. B1, 2012.

[17] J. Xu, Z. Zheng, X. Xiao, and Z. Li, "Crack propagation and coalescence due to dual nonpenetrating surface flaws and their effect on the strength of rock-like material," Journal of Geophysics and Engineering, vol. 15, no. 3, pp. 938-951, 2018.

[18] S. J. Du, J. D. Zhu, and H. T. Zhi, "Shear tests on rock joints under different shear deformation histories," Chinese Journal of Rock Mechanics \& Engineering, vol. 1, pp. 56-60, 2006.

[19] A. Bobet and H. H. Einstein, "Fracture coalescence in rocktype materials under uniaxial and biaxial compression," International Journal of Rock Mechanics and Mining Sciences, vol. 35, no. 7, pp. 863-888, 1998.

[20] H. Jan, W. S. Zhu, S. C. Li et al., "Preliminary study on CT realtime test for simulating hydraulic fracturing of jointed rock mass," Journal of Rock Mechanics and Engineering, vol. 11, pp. 1655-1662, 2002.

[21] C. C. Xia, W. M. Xiao, and Z. Z. Ding, "Weakening of rock bridge and correction of joint surface fluctuation angle for jennings strength criterion of nonpenetrating joints," Journal of Rock Mechanics and Engineering, vol. 3, pp. 485-492, 2010.

[22] S. W. Bai, W. Z. Ren, D. X. Feng et al., "Failure mechanism and strength characteristics of closed discontinuous jointed rock mass under plane stress," Journal of Rock Mechanics and Engineering, vol. 6, pp. 635-640, 1999.

[23] W. Z. Ren, G. S. Wang, S. W. Bai et al., "Study on the direct shear strength of coplanar closed discontinuous jointed rock mass," Journal of Rock Mechanics and Engineering, vol. 10, pp. 1667-1672, 2003.

[24] B. Hu, S. J. Wang, and X. L. Liu, "Direct shear strength model of coplanar discontinuous jointed rock mass," Journal of Jiangsu University (Natural Science Edition), vol. 5, pp. 601605, 2012.

[25] R. Yoshinaka, T. V. Tran, and M. Osada, "Non-linear, stressand strain-dependent behavior of soft rocks under cyclic triaxial conditions," International Journal of Rock Mechanics and Mining Sciences, vol. 35, no. 7, pp. 941-955, 1998.

[26] Y. Bao and J. F. Li, "Application of dem for modelling crack initiation and propagation in rock masses with open and closed flaws," Journal of Mechanics (English Edition), vol. 3, pp. 282-293, 2014.

[27] Y. Zhao, Y. Wang, W. Wang, W. Wan, and J. Tang, "Modeling of non-linear rheological behavior of hard rock using triaxial rheological experiment," International Journal of Rock Mechanics and Mining Sciences, vol. 93, pp. 66-75, 2017.

[28] J. Bi, X. P. Zhou, and Q. H. Qian, "The 3D numerical simulation for the propagation process of multiple pre-existing flaws in rock-like materials subjected to biaxial compressive loads," Rock Mechanics and Rock Engineering, vol. 49, no. 5, pp. 1611-1627, 2016.
[29] C. L. Wang, L. H. Pan, Y. Zhao, Y. Zhang, and W. Shen, "Analysis of the pressure-pulse propagation in rock: a new approach to simultaneously determine permeability, porosity, and adsorption capacity," Rock Mechanics and Rock Engineering, vol. 52, no. 11, pp. 1-17, 2019.

[30] M. Adams and G. Sines, "Crack extension from flaws in a brittle material subjected to compression," Tectonophysics, vol. 49, no. 1-2, pp. 97-118, 1978.

[31] T. Jin-Zhou, Y. Sheng-Qi, W.-L. Tian, and Y. Tao, "Effect of confining pressure on mechanics and deformation behavior of sandstone containing a single inclined joint," European Journal of Environmental and Civil Engineering, In press.

[32] Q.-X. Meng, H.-L. Wang, W.-Y. Xu, and Y.-L. Chen, "Numerical homogenization study on the effects of columnar jointed structure on the mechanical properties of rock mass," International Journal of Rock Mechanics and Mining Sciences, vol. 124, Article ID 104127, 2019.

[33] F. Zhang, B. Damjanac, and S. Maxwell, "Investigating hydraulic fracturing complexity in naturally fractured rock masses using fully coupled multiscale numerical modeling," Rock Mechanics and Rock Engineering, vol. 52, no. 12, pp. 5137-5160, 2019.

[34] W. Zhou, X. Shi, X. Lu, C. Qi, B. Luan, and F. Liu, "The mechanical and microstructural properties of refuse mudstone-GGBS-red mud based geopolymer composites made with sand," Construction and Building Materials, vol. 253, Article ID 119193, 2020.

[35] Y. Zhao, L. Zhang, W. Wang, C. Pu, W. Wan, and J. Tang, "Cracking and stress-strain behavior of rock-like material containing two flaws under uniaxial compression," Rock Mechanics and Rock Engineering, vol. 49, no. 7, pp. 26652687, 2016.

[36] F. P. Yuan, V. Prakash, and T. Tullis, "Origin of pulverized rocks during earthquake fault rupture," Journal of Geophysical Research Solid Earth, vol. 116, no. B6, 2011.

[37] X. Wang, W. Yuan, Y. Yan, and X. Zhang, "Scale effect of mechanical properties of jointed rock mass: a numerical study based on particle flow code," Geomechanics and Engineering, vol. 21, no. 3, pp. 259-268, 2020.

[38] C. Liu, "Study on The Weakening Effect of Mechanical Properties of Rock Bridges In Non-onnected Jointed Rock Masters," Guizhou University, Guiyang, China, 2017.

[39] Y. M. Liu, "Study on the Extension and Transfixion of Rock Masses with Non through Joints Based on Direct Shear Test," Tongji University, Shanghai, China, 2007.

[40] S. Q. Yang, Y. Z. Jiang, W. Y. Xu, and X. Q. Chen, "Experimental investigation on strength and failure behavior of precracked marble under conventional triaxial compression," International Journal of Solids and Structures, vol. 45, no. 17, pp. 4796-4819, 2008.

[41] W. Yao, Y. Y. Cai, J. Yu, J. Zhou, S. Liu, and B. Tu, "Experimental and numerical study on mechanical and cracking behaviors of flawed granite under triaxial compression," Measurement, vol. 145, pp. 573-582, 2019.

[42] S.-Q. Yang, X.-R. Liu, and H.-W. Jing, "Experimental investigation on fracture coalescence behavior of red sandstone containing two unparallel fissures under uniaxial compression," International Journal of Rock Mechanics and Mining Sciences, vol. 63, pp. 82-92, 2013.

[43] C. Zhao, J. S. Tian, T. H. Song et al., "Crack propagation and damage evolution characteristics of rock under uniaxial compression based on global strain field analysis," Journal of Rock Mechanics and Engineering, vol. 4, pp. 763-769, 2015. 
[44] C. Zhao, F. M. Liu, J. S. Tian et al., "Research on the law of single crack propagation and damage evolution of rock based on uniaxial compression test," Journal of Rock Mechanics and Engineering, vol. S2, pp. 3626-3632, 2016. 